BNL-97197-2012 -IR

\title{
Investigation into Cause of Cs-137 Source Leakage
}

\author{
Carl Czajkowski \\ John Young \\ Tyler Rovig
}

April 2012

Department of Nonproliferation and National Security Nonproliferation and Homeland Security Field Support

Brookhaven National Laboratory

\section{U.S. Department of Energy DOE - Office of Science}

Notice: This manuscript has been authored by employees of Brookhaven Science Associates, LLC under Contract No. DE-AC02-98CH10886 with the U.S. Department of Energy. The publisher by accepting the manuscript for publication acknowledges that the United States Government retains a non-exclusive, paid-up, irrevocable, world-wide license to publish or reproduce the published form of this manuscript, or allow others to do so, for United States Government purposes. 


\section{DISCLAIMER}

This report was prepared as an account of work sponsored by an agency of the United States Government. Neither the United States Government nor any agency thereof, nor any of their employees, nor any of their contractors, subcontractors, or their employees, makes any warranty, express or implied, or assumes any legal liability or responsibility for the accuracy, completeness, or any third party's use or the results of such use of any information, apparatus, product, or process disclosed, or represents that its use would not infringe privately owned rights. Reference herein to any specific commercial product, process, or service by trade name, trademark, manufacturer, or otherwise, does not necessarily constitute or imply its endorsement, recommendation, or favoring by the United States Government or any agency thereof or its contractors or subcontractors. The views and opinions of authors expressed herein do not necessarily state or reflect those of the United States Government or any agency thereof. 


\section{Investigation into Cause of Cs-137 Source Leakage}

April 6, 2012

Carl Czajkowski

John Young

Tyler Rovig 


\subsection{Introduction:}

During the morning of September 28, 2011 a pig containing a sealed source used for source checking detectors, tipped over in the Collider-Accelerator Department (C-AD) Radiological Control van. Several hours later, the Radiological Control Technician (RCT) detected low levels of radioactivity on his shoes, and the floor mat of the vehicle, as well as a personal vehicle owned by a facilities and operations (F\&O) tradesman who took the RCT to lunch at the BNL cafeteria. Areas that were checked for contamination included offices, work station, RCTs themselves, the tradesman and the cafeteria. Several areas of contamination were detected in the parking lot, the floor of the source storage building, and also detectors where the source had been used that day. All areas were secured or decontaminated. The initial results reported in the afternoon of 9/28 were preliminary, and the final determination on its report ability was deferred until more information could be obtained after additional smear results were performed.

All occupants of the building were surveyed and no further contamination was found. The source had last been leak checked in July, 2011.

Smear samples from all areas were analyzed on the morning of 9/29, and found to be below 10 CFR835 Appendix D limits.

\section{2-15-12, Update: On September 29, 2011, BNL declared the event reportable as a} Significance Category 3 occurrence. On Friday, September 30, 2011, after gathering further details, including verification of initial measurements and return of the personal vehicle to $B N L, B N L$ raised the event to a Significance Category 2 occurrence. The ORPS notification report was submitted to DOE on Monday, October 3, 2011.

Pursuant to finding a root cause into the source of the leaks, a metallurgical assessment of the source was conducted by Dr. Carl Czajkowski (BNL Senior Metallurgist), this evaluation was made possible through the efforts of both J. Young and T. Rovig.

\subsection{Examinations:}

The pertinent observations follow:

- Figure 1 is a photograph of the source that leaked. It is approximately 6 inches (15.34 $\mathrm{cm}$ ) in length. The source is a copper alloy, probably brass that has machined knurling off-center on the source.

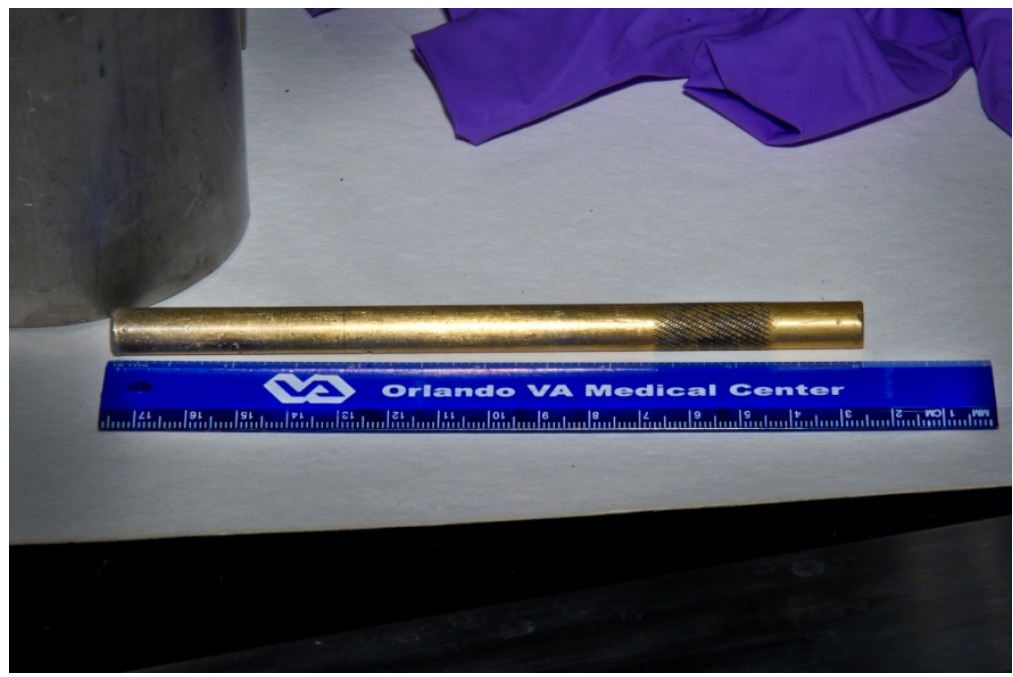

Figure 1. Photograph of the leaking source. 
- The source was approximately $1 / 2$ inch $(1.27 \mathrm{~cm})$ in diameter as is represented in Figure 2 .

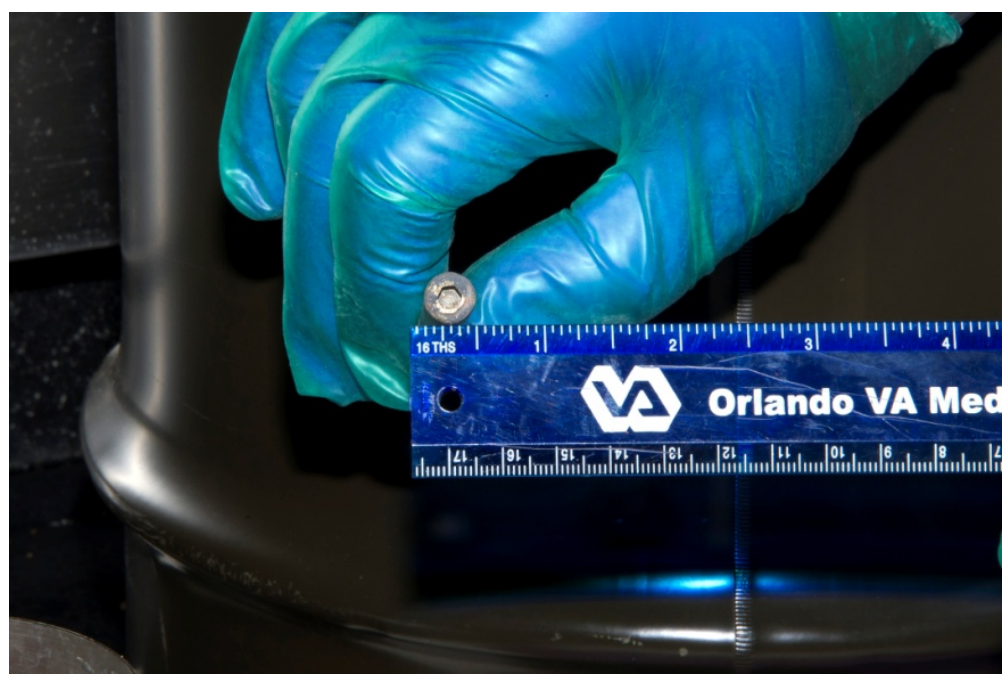

Figure 2. Photograph showing diameter of source and Allen-head type fitting on the end,

- The source had an Allen-head type fitting on the end opposite the knurled side of the source. (Figure 2).

- The source was routinely "dropped" into the lead pig. A photograph of the "pig” is shown in Figure 3.

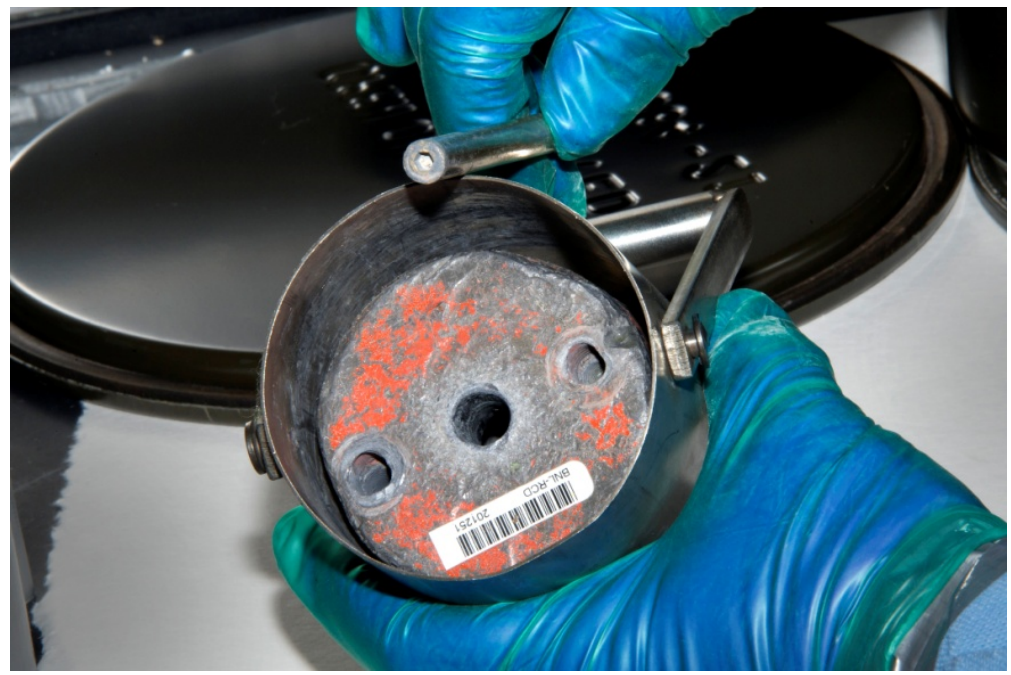

Figure 3. Photograph of the "pig" and source.

- The source would normally be placed in the center hole of the "pig". Its relative position in the "pig" is shown in Figure 4. 


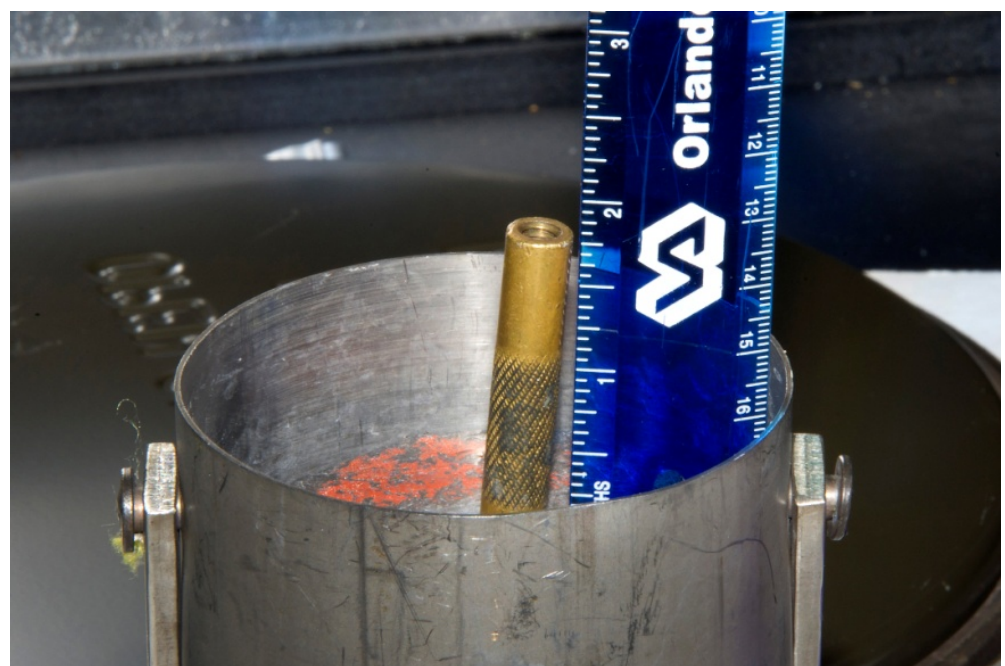

Figure 4. Photo showing "pig” and demonstrates how the source would typically be inserted.

- The source was examined by radiography. The radiographs showed two interesting items Figure 6 is the overall radiograph of the source. Figure 5. is a close up area of the threaded section.

0 The first was an area that on initially review resembled a large area of possible pitting on the surface of the source. (3/4 of the way down on Figure 5). On further examination, this area is probably an "artifact" associated with the radiography techniques utilized. Figure 5.

o The second item was the amount of clearance visible between the threads in the close up radiograph. Figure 5.

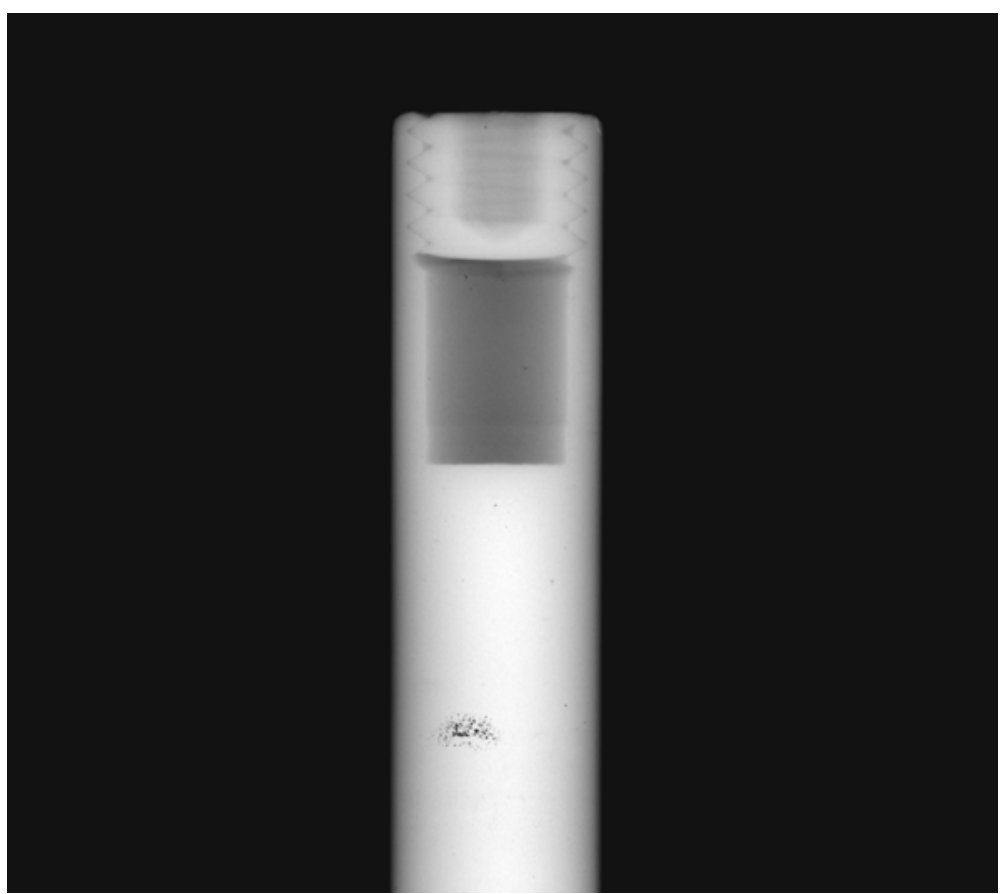

Figure 5. Close-up of threaded area in source and the artifact below threads. Note the clearance between threads. 


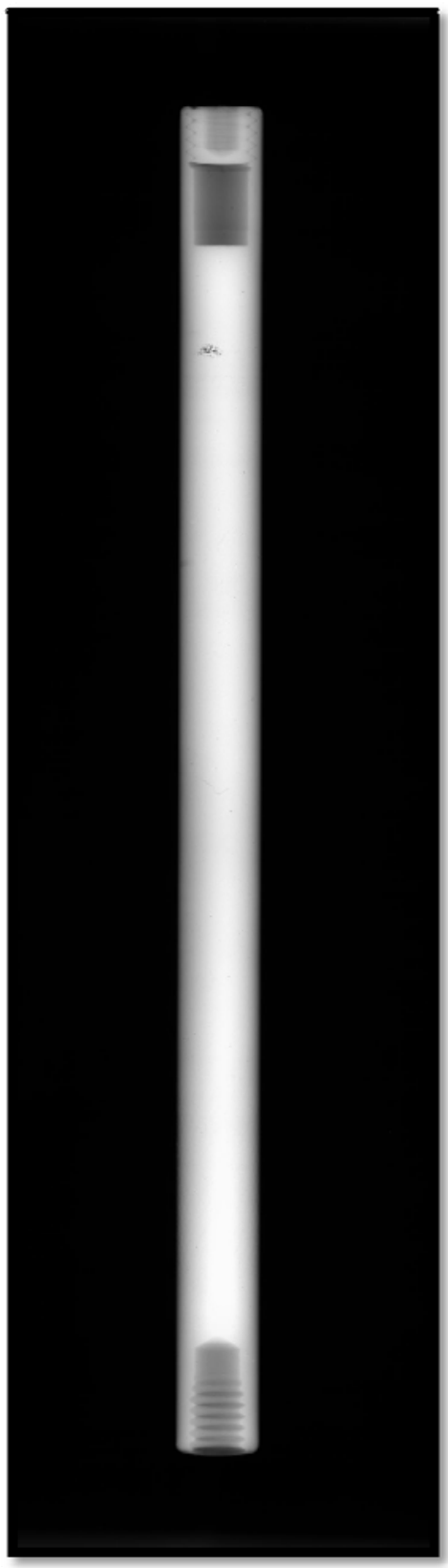

Figure 6. Overall radiograph of the source.

- The observation of the Allen-head type screw on one end of the source and the clearances observed indicated the possibility that the screw end was not sufficiently tightened and that this might have contributed to the source leaking. It was decided at this juncture that a physical examination needed to be performed on the source. This examination was to include:

o A complete visual inspection of the source, with special attention paid to any gouges, pits, or holes in evidence.

o A tightening of the Allen-head screw to determine if it was loose or tightly inserted. 
- Testing for a leakage path, by placing a piece of tape was across the Allenhead screw (after cleaning) and then gently tapping the end that was taped on a surface. This was then to be repeated after tightening the screw.

- Photographing any of the gouges, cuts or abrasions that might have contributed to the leakage.

- The first steps in performing the visual inspection/failure analysis required the appropriate safety training being accomplished, PRIOR to any actual work on the source. This entailed a review of contamination controls review and taking the Contamination Challenge Examination (HP-RWT-350CB).

o After the challenge exam was taken and passed, a review of the intended examination procedures were thoroughly discussed with RadCon personnel and an examination of the fume hood where the work was to be performed was accomplished.

o A practical “dress-out” procedure for entry and exit of the examination area was administered, in addition to a review of the RWP with RCD personnel.

o This review of the area indicated that a (for close-up pictures) of the source, a laptop computer attached to a small disposable microscope would be used in the examination.

0 A review of the radiological hazards was performed (Figure 7a and b), including activity levels of various smears. These were then factored into the actual examination techniques utilized.

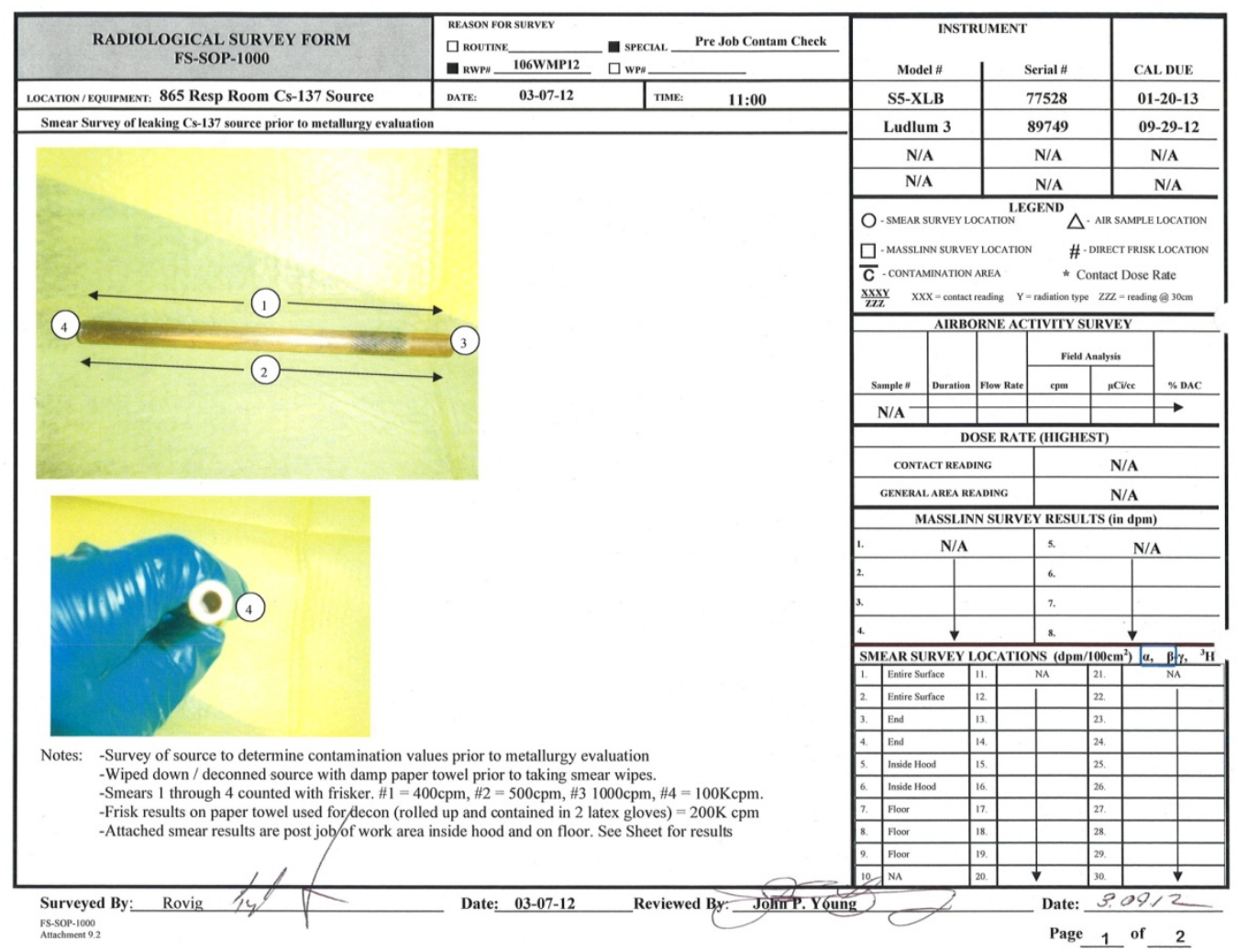

Figure 7a. Radiological Survey form for "leaking source” evaluation. 


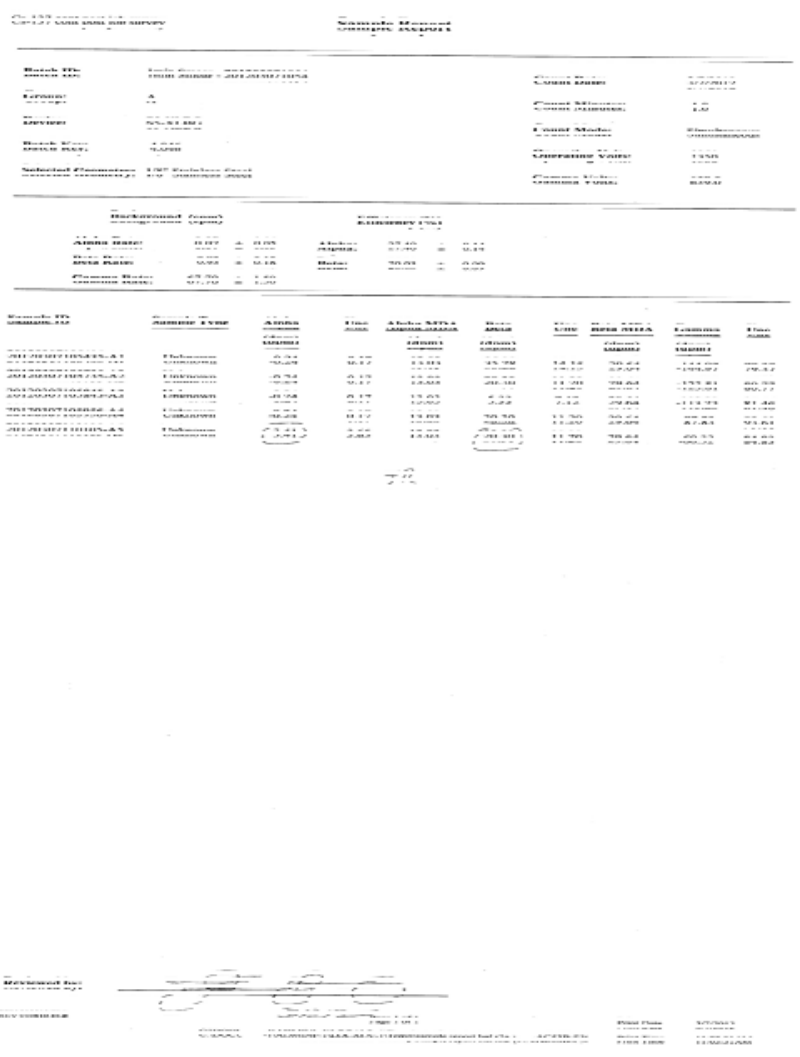

Figure 7b. Sample report showing $\beta-\gamma$ from smears.

- The source was then examined visually for signs of obvious leakage or areas that might have contributed to the leaking. The source definitely showed signs of wear and impact damage consistent with $30+$ years of use. Various deep scratches, gouges and pits were examined at higher magnification using a disposable microscope and the pictures recorded on a desktop computer. Figures 8, 9, 10 and 11 are representative photographs of the most deeply "gouged/abraded/cut" areas examined. In no case was the damage severe enough to allow access to the source material on the inside of the brass tube.

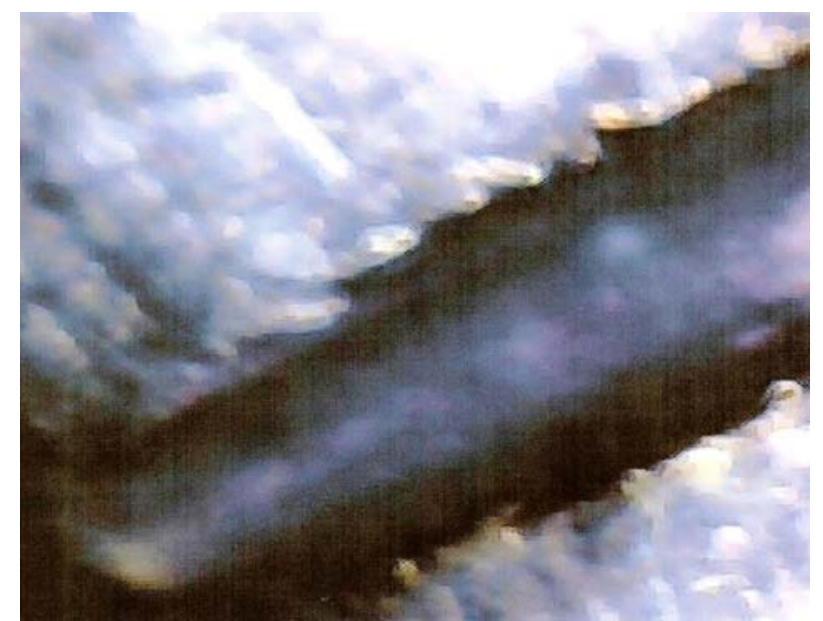

Figure 8. Photomicrograph of a "gouged" area of the tube, NO apparent leakage. 


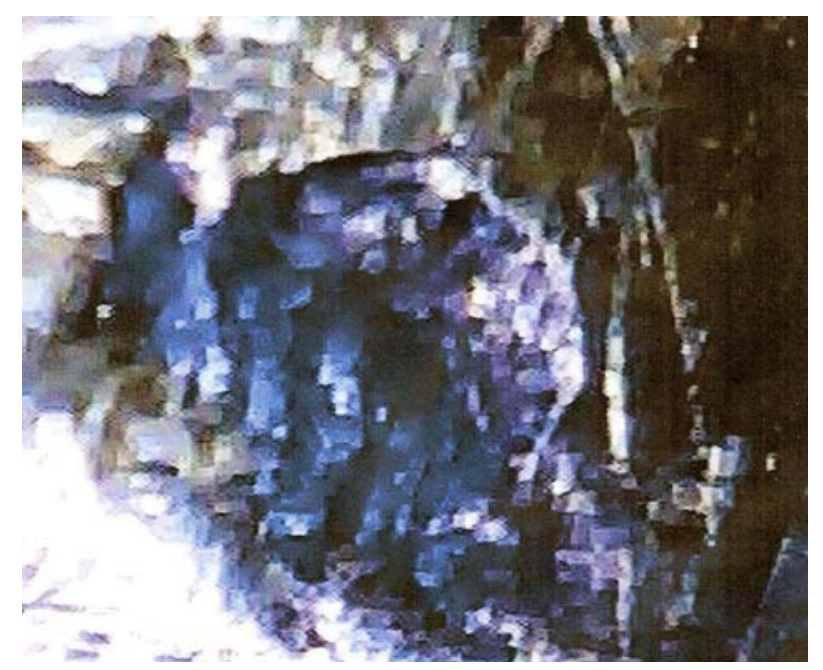

Figure 9. Photomicrograph of a “pitted area”. NO apparent leakage.

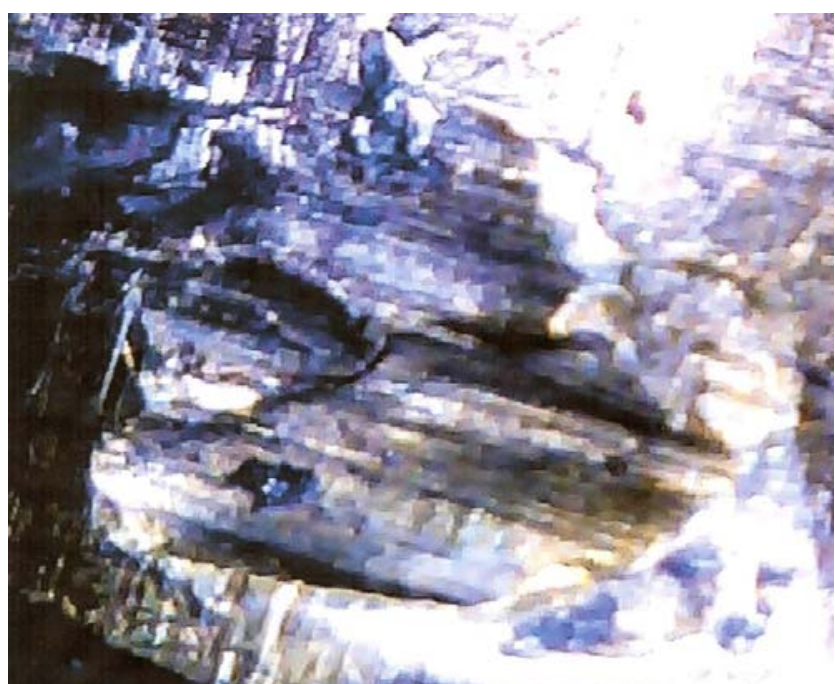

Figure 10. Photomicrograph of a "gouged” area of the tube, NO apparent leakage.

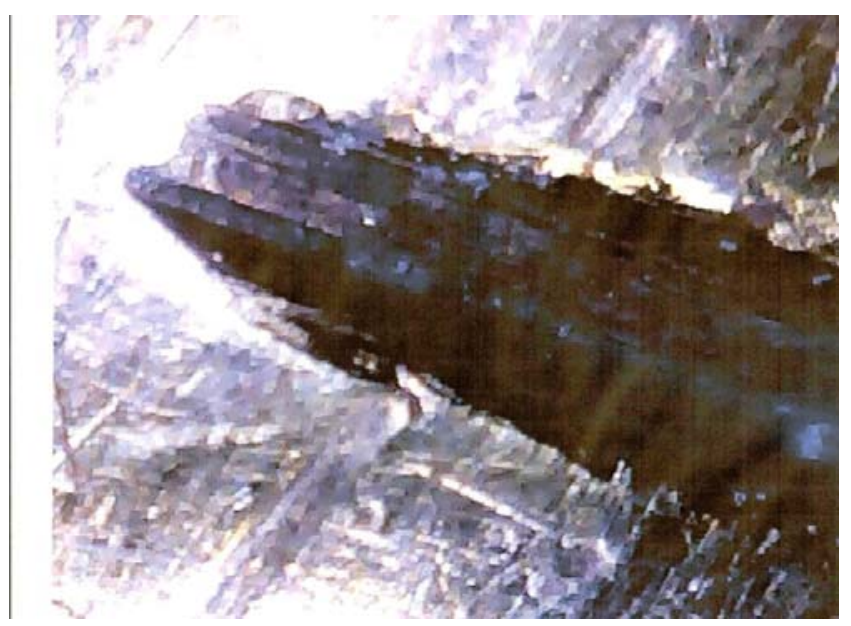

Figure 11. Photomicrograph of a "gouged" area of the tube, NO apparent leakage. 
- The Allen-head end of the tube was cleaned with duct tape to remove loose contamination and then covered with tape and then "tapped" on a hard surface. The tape was removed and then radiologically examined. The readings indicated a count of $\sim 5,000$ counts per minute (cpm). The end of the tube was then re-cleaned with duct tape to remove loose contamination, the Allen-head screw tightened and then re-covered with tape and again "tapped" on a hard surface. Readings taken on this piece of tape indicated a count of $\sim 10,000$ counts per minute (cpm). The end of the tube was then re-cleaned again with duct tape to remove loose contamination, the Allen-head screw re-tightened and then re-covered with tape and again "tapped" on a hard surface. Readings taken on this piece of tape indicated a count of $\sim 100,000$ counts per minute (cpm). The $~ 100,000$ counts per minute $(\mathrm{cpm})$ reading is quite similar to the original smears on the survey Figure 7a.

o With these "unusual results" recorded, the examination was terminated.

\subsection{Discussion and Conclusions}

- Meetings with BNL RCD personnel indicate that this particular source is a "one of a kind" sealed source.

o In actuality, it is extremely difficult to refer to this particular source as a sealed source, since both ends have threaded fittings.

- This being the case, one must ask, how can a brass tube filled with a cesium salt leak? The mechanisms for this source leaking narrow down to the threaded ends as no punctures reaching the inner core of the source were observed. (Even the deepest cuts and abrasions were relatively shallow). Since there was no "smoking gun" observed during the evaluation, but it was obvious that the source had definitely received a good deal of physical abuse over its lifetime. Coupling this with the routine practice of dropping the source into the "pig" does give rise to a probable cause of the leakage:

0 The radiograph of the threaded end (Figure 5) does indicate a fairly large gap in the interference fit of the threads on the source end. So, even after tightening the end, there are probably numerous crystals lodged in between the threads that have migrated during the numerous impacts that the source must have received during its lifetime. This hypothesis is somewhat substantiated by the increase in loose contamination after a second "rap" on a hard surface. 